\title{
Kekayaan Spesies Kelelawar Ordo Chiroptera Di Gua Wilayah Selatan Pulau Lombok, Nusa Tenggara Barat
}

\section{The Richness of Bat Species Order Chiiroptera in the Southern Caves of Lombok Island West Nusa Tenggara}

\author{
Siti Rabiatul Fajri ${ }^{1}$, Agil Al Idrus ${ }^{2}$, Gito Hadiprayitno ${ }^{2}$ \\ ${ }^{1}$ Program Pascasarjana Magister Pendidikan IPA Universitas Mataram \\ ${ }^{2}$ Program Studi Pendidikan Biologi FKIP Universitas Mataram \\ *email: rabiatul_fajri@yahoo.com
}

Manuscript received: 16 Mei 2013 Revision accepted: 11 Juli 2014

\begin{abstract}
The research was conducted in order to determine the species richness in the cave region of southern island of Lombok. The study was conducted through a survey technique at 5 caves located in the southern region of the island of Lombok the Cave Gale-Gale, Buwun Cave, Cave Kenculit, Raksasa Cave and Cave Pantai Surga. The survey was conducted from March to May 2014. Sampling bat for identification as done by using the mist nets. Bats were caught identified further in the Laboratory of Biological Science, University of Mataram. The results show that has found 6 Family with 12 species. Based on identification of 12 species were found in the caves of the area south of the island of Lombok, there are 9 species ever discovered by Kitchener (2002) in his study on the island of Lombok is Hipposiderosater, Rhinolopussimplex, Rosettusamplxicaudatus, Hipposiderosdiadema, Eonycterisspeleae, Miniopteruspusillus, Taphazousmelanopogon, Macroglossusminimus, and Murinacyclotis, Hipposiderosbicolor, Rhinopoma microphyllum and Phoniscus atrox.
\end{abstract}

Keywords: bat, cave, southern region of the island of Lombok

\section{LATAR BELAKANG}

Kelelawar merupakan salah satu ordo dari kelas mamalia yang memiliki kemampuan berpindah dengan menggunakan sayap (terbang). Secara umum, kelelawar yang tergolong ke dalam Ordo Chiroptera dapat dikelompokkan ke dalam 2 Sub ordo yaitu Sub ordo Megachiroptera (Pemakan buah-buahan) dan sub ordo Microchiroptera (Pemakan serangga) (Suyanto, 2001). Kelelawar yang ada di Indonesia diperkirakan mencapai 230 spesies atau $21 \%$ dari spesies kelelawar yang ada di dunia. Spesies tersebut diantaranya 77 spesies dikelompokkan ke dalam sub ordo Megachiroptera sedangkan 153 spesies dikelompokkan ke dalam sub ordo Microchiroptera (Suyanto, 2001).

Suyanto (2001) menyebutkan bahwa 20\% kelelawar sub ordo Megachiroptera dan lebih dari 50\% kelelawar sub ordo Microchiroptera memilih tempat bertengger di dalam gua. Keberadaan kelelawar di dalam gua, menurut Wijayanti (2011) dapat berperan sebagai kunci penyedia energi ekosistem (key factor in cycle energy) bagi organisme yang ada di dalam gua.Oleh sebab itu, apabila ekosistem gua tidak dikelola dengan baik, dapat mengganggu keseimbangan ekosistem, baik ekosistem yang ada di dalam gua maupun ekosistem yang ada di luar gua.

Beberapa hasil penelitian menginformasikanbahwa Pulau Lombok merupakan salah satu pulau yang memiliki keanekaragaman spesies kelelawar cukup tinggi.
Angkatan Laut Amerika Serikat melaporkan bahwa pada tahun 1978-1979 ditemukan spesies Eonycteris spelaea, Dobsonia peronii, Chaerephon plicata, Schotophilus kuhlii dan Myotis muricola yang ada di Pulau Lombok. Kemudian pada tahun 1988 dilakukan penelitian kelelawar di 5 lokasi yaitu di Taman Suranadi (Gua Batu Kota), Batu Koq (Gua Sawa), Pelangan (Gua Pantai berkapur), Kuta (Gua yang berada $4 \mathrm{~km}$ ke arah barat kuta dan gua Gunung Saung) dan Gunung Rinjani (Gua Susu dan Gua Lawa). Hasil penelitian menunjukkan bahwa telah ditemukan 36 spesies kelelawar dan spesies yang paling khas ialah spesies Pteropus lombocensis dan Pipistrellus tenuis swelanus (Kitchener, dkk, 2002).

Fajri dan Hadiprayitno (2013) menemukan spesies Hipposideros bicoloryang merupakan spesies kelelawar yang belum ditemukan dalam Kitchener, dkk.(2002). Temuan tentang spesieskelelawar tersebut di Pulau Lombok menambah jumlah spesies kelelawar yang belum dilaporkan dalam penelitian-penelitian sebelumnya.

Tidak sedikit gua di Pulau Lombok yang diperkirakan memiliki spesies kelelawar.Namun belum dieksplorasi secara maksimal.Bahkan terdapat gua yang ada di Pulau Lombok ditemukan runtuh (rusak) dan gua yang sudah tidak dihuni oleh kelelawar, terutama gua-gua yang ada di wilayah selatan Pulau Lombok.Hal ini terjadi karena adanya penambangan yang dilakukan oleh masyarakat.Aktivitas penambangan yang dilakukan oleh 
masyarakat di beberapa gua yang ada di wilayah selatan Pulau Lombok ini patut diduga sebagai salah satu penyebab menurunnya populasi kelelawar di wilayah tersebut. Apabila tidak dilakukan upaya pencegahan tidak menutup kemungkinan akan mengakibatkan terjadinya kepunahan secara lokal pada spesies-spesies kelelawar tertentu. Sehingga terjadi ketidakseimbangan ekosistem.Terkait hal tersebut dipandang perlu untuk melakukan inventarisasi kekayaan spesies kelelawar gua di wilayah selatan yang ada di Pulau Lombok.

\section{METODE}

Penelitian dilakukan pada bulan Maret sampai dengan Mei 2014 di 5 gua wilayah selatan Pulau Lombok. Kelima gua tersebut ialah Gua Gale-Gale (Lombok Tengah), Gua Buwun (Lombok Tengah), Gua Kenculit (Lombok Tengah), Gua Raksasa (Lombok Timur), dan Gua Pantai Surga (Lombok Timur).

Bahan yang digunakan dalam penelitian terdiri dari alkohol $70 \%$ dan kapas yang digunakan untuk membius dan mengawetkan sampel kelelawar untuk koleksi spesimen. Alat yang digunakan untuk mengoleksi sampel kelelawar adalah jaring kabut (Mist Net), tali, tiang sepanjang 2,5 - 3 m untuk memasang jaring kabut, jaring bertangkai panjang, kantong blacu, masker, gunting, pinset panjang, buku identifikasi dan kamera.

Pengambilan sampel spesies kelelawar dilakukan dengan metode Trapping menggunakan Mist net (Wiantoro, 2009; Suripto, dkk.; Maharadarunkamsi, 2011; Suyanto, 2001). Penangkapan kelelawar dilakukan pada saat kelelawar memulai aktivitasnya pada sore hari.Data kekayaan spesies dilakukan mulai pukul 18.30 sampai dengan 19.00 WITA.

Kelelawar yang tertangkap selanjutnya diidentifikasi di Laboratorium Biologi FMIPA Universitas Mataram untuk mengetahui jenisnya mengacu pada Suyanto (2001).

\section{HASIL DAN PEMBAHASAN}

Spesies kelelawar gua wilayah selatan Pulau Lombok yang ditemukan selama penelitian terdiri atas 6 famili dengan 12 spesies (Tabel 1).

Tabel 1. Spesies Kelelawar Gua di Wilayah Selatan Pulau Lombok

\begin{tabular}{|c|c|c|c|c|}
\hline No & Sub Ordo & Famili & & Spesies \\
\hline \multirow[t]{3}{*}{1} & Megachiroptera & Pteropodidae & 1 & Macroglossus minimus \\
\hline & & & 2 & Eonycteris speleae \\
\hline & & & 3 & Rousettus amplexicaudatus \\
\hline \multirow[t]{9}{*}{2} & Microchiroptera & Hipposideridae & 4 & Hipposederos bicolor \\
\hline & & & 5 & Hipposederos ater \\
\hline & & & 6 & Hipposederos diadema \\
\hline & & Vespertilionidae & 7 & Miniopterus pusillus \\
\hline & & & 8 & Phoniscus atrox \\
\hline & & & 9 & Murina cyclotis \\
\hline & & Rhinolophidae & 10 & Rhinolopus simplex \\
\hline & & Emballonuridae & 11 & Taphozous melanopogon \\
\hline & & Rhinopomatidae & 12 & Rhinopoma microphyllum \\
\hline
\end{tabular}

Hasil penelitian pada Tabel 1 menunjukkan bahwa Sub ordo Microchiroptera mengandung lebih banyak spesies kelelawar dibandingkan dengan Sub ordo Megachiroptera. Hal ini sejalan dengan hasil penelitian yang dilakukan oleh Suyanto (2001) yang menyebutkan bahwa 20\% kelelawar sub ordo Megachiroptera dan lebih dari $50 \%$ kelelawar sub ordo Microchiroptera ditemukan di dalam gua. Kebanyakan jenis Microchiroptera bersarang di gua dalam jumlah besar.

Beberapa jenis kelelawar memilih gua sebagai tempat bersarang karena kondisi gua yang lembab, suhu stabil, dan jauh dari kebisingan.Pada kondisi yang demikian, kelelawar kelompokMicrochiroptera dapat meminimalkan kekurangan air akibat evaporasi, dapatmemilih suhu yang tepat untuk tubuhnya, dan dapat menghindari kebisingan yangdapat mengganggu bahkan dapat menyebabkan kematian(Altringham, 1996 dan Zahn \& Hager, 2005).Terdapat banyak penelitian yang melaporkan sub ordo Microchiroptera lebih banyak ditemukan di dalam gua seperti Wijayanti (2011) di gua-gua Karst Gombong Jawa Tengah menyebutkan bahwa terdapat 4 spesies sub ordo Megachiroptera dan 11 spesies anggota sub ordo Microchiroptera. Riswandi (2012) di Gua TNAP menyebutkan bahwa 4 spesies sub ordo Megachirop-tera dan 13 spesies anggota sub ordo Microchiroptera. Bagus \& Ahmadi (2012) menyebutkan bahwa dari 20 spesies tertangkap di Gua Lawa terdapat seluruhnya merupakan anggota sub ordo Microchiroptera dan Nurfitrianto, dkk. (2013) di gua Lawa dari 5 spesies yang berhasil diidentifikasi 1 spesies anggota dari sub ordo Megachiroptera dan 4 spesies anggota sub ordo Microchiroptera.Selain itu, pada hasil penelitian juga menyebutkan bahwa anggota subordo Microchiroptera memiliki spesies terbanyak yang bertengger di dalam gua wilayah selatan Pulau Lombok ialah anggota dari Famili Hipposideridae dan Vespertilionidae, masing-masing 3 spesies. Sedangkan Famili yang lain hanya masingmasing 1 spesies. Suyanto (2001) menyebutkan bahwa Famili Hipposideridae dan Vespertilionidae memiliki anggota spesies paling banyak dari pada marga lainnya. Beberapa penelitian lain yang pernah melaporkan keberadaan kedua Famili tersebut diantaranya di gua Karst 
Gombong Famili Hipposideridae sebanyak 6 spesies dan Famili Vespertilionidae seb-anyak 4 spesies (Wijayanti, 2011), di Gua TNAP Famili Hipposideridae sebanyak 4 spesies dan Famili Vespertilionidae sebanyak 4 spesies (Riswandi, 2012) dan di gua Malagasy Famili Hipposideridae sebanyak 9 spesies dan Famili Vespertilionidae sebanyak 9 spesies (Simmons, 2005).

Spesies kelelawar yang ditemu-kan dalam penelitian ini, beberapa diantaranya ditemukan juga dalam penelitian yang dilakukan oleh Kitchener (2002) dan Fajri \& Hadiprayitno (2013). Ditemukannya spesies kelelawar yang sama dengan penelitian sebelumnya dapat disebabkan oleh beberapa factor, beberapa factor tersebut diantaranya ialah kondisi lingkungan yang sesuai, makanan yang masih tersedia, dan ketidakhadiran predator, sehingga masih banyak kelelawar yang masih hidup dan bertahan di tempat tersebut. Selain itu kondisi mikroklimat yang sesuai dengan kebutuhan kelelawar. Seckerdieck et al. (2005) membuktikan bahwa kelelawar mempunyai home instink yang kuat, tempat tinggal yang dipilih kelelawar dipertahankan sampai beberapa generasi. Namun demikian apabila tempat tinggal mendapat ganggguan dan kelelawar tidak nyaman dan aman, tempat tinggal ini akan ditinggalkan (Willis \& Brigham, 2004).

Terdapatnya spesies kelelawar yang tidak ditemukan dalam penelitian ini dengan penelitian sebelumnya di Pulau Lombok seperti Dobsonia peroni, Acerodon macloti, Pteropus vampyrus, Pteropus alecto, Pteropus lombocensis, Aethalopus, Cynopterus sp, Chaerephon plicata, Megaderma spasma, dan Tylonycteris pachypus.Kitchener (2002) dapat disebabkan oleh banyak faktor. Faktor utama ialah penelitian ini hanya berkonsentrasi pada kelelawar yang menghuni gua, dengan demikian hanya menginventarisasi spesies kelelawar yang hanya ditemukan di gua, meskipun banyak sekali habitat kelelawar seperti di kolong atap rumah, terowongan, bawah jembatan, rerimbunan daunan, gulungan pohon pisang/palem, celah bambu, lubang batang pohon baik yang hidup ataupun mati dan pohon besar. Selain itu penelitian ini hanya berkonsentrasi di wilayah selatan Pulau Lombok. Faktor lain sebagai penyebab tidak ditemu-kannya beberapa spesies kelelawar di Pulau Lombok adalah terganggunya habitat yaitu kawasan gua yang sebagai habitat kelelawar yang berada di wilayah selatan Pulau Lombok telah mengalami kerusakan dan gangguan seperti terjadinya penambangan di kawasan gua baik di dalam maupun di luar gua.

Ditemukannya 2 spesies kelelawar yang belum pernah ditemukan pada penelitian sebelumnya dapat disebabkan oleh beberapa faktor diantaranya ialah faktor habitat. Rhinopoma microphyllum tinggal di gua Buwun Gunung Prabu Kuta. Gua Buwun terletak di barat pantai kuta, gua tersebut tidak diketahui keberadaannya oleh banyak orang karena keadaan gua yang tertutup rerimbunan daun, pohon dan semak belukar. Hal ini juga sependapat dengan yang diungkap-kan oleh Hutson,et al. (2008) Rhinopoma microphyllum merupakan kelelawar yang hidup atau menyukai habitat yang tertutup oleh rerimbunan pohon dan semak dalam vegetasi hutan primer. Rhinopoma microphyllum merupakan spesies kelelawar yang telah masuk ke dalam daftar IUCN Red List dengan setatus Least Concern (LC) atau paling sedikit. Rhinopoma microphyllum merupakan kelelawar yang jarang sekali dijumpai dan jumlah yang sedikit ditemui di beberapa negara.

Phoniscus atrox ditemukan di dua lokasi di wilayah selatan Pulau Lombok yaitu di Gua Buwun dan Gua Pantai Surga. Gua tersebut merupakan gua yang samasama jauh dari jangkauan manusia. Phoniscus atroxtidak pernah ada laporan sebelumnya ditemukan di dalam guagua di Indonesia. Namun dibeberapa hutan pernah dilaporkan seperti di hutan primer sumatera (Suyanto, 2001). Laporan terakhir yang dipublikasikan bahwa Phoniscus atroxditemukan di hutan yang rusak pada ketinggian $150 \mathrm{dpl}$ di Thailand (Thong, at al., 2006 dalam Hutson, et al. (2008)). Phoniscus atroxtelah masuk ke dalam daftar IUCN Red List dengan statusNear Threatened (NT) atau hampir punah di Indonesia dan Malaysia (Fleming \& Paul, 2009). Hal ini menjadi menarik karena Phoniscus atroxditemukan di dua lokasi di wilayah selatan Pulau Lombok meskipun dalam jumlah sedikit.

Ditemukannya spesies kelelawar Rhinopoma microphyllum dan Phoniscus atroxdalam penelitian ini dapat memberikan kontribusi penambahan jumlah spesies kelelawar yang ditemukan di Pulau Lombok. Spesies kelelawar yang ditemukan di Pulau Lombok yang dipublikasikan oleh Kitchener (2002) berjumlah 36 spesies. Selanjutnya Spesies kelelawar yang ditemukan di Pulau Lombok yang dipublikasikan oleh Fajri dan Hadiprayitno (2013) telah menemukan 1 spesies kelelawar baru yang belum pernah dilaporkan pada penelitian-penelitian sebelumnya. Mela-lui penemuan 2 spesies kelelawar pada penelitian ini dengan penelitian yang dilakukan oleh Fajri dan Hadiprayitno (2013)akan menambah koleksi spesies kelelawar di Pulau Lombok menjadi 39 spesies.

Pada penelitian ini juga terlihat terdapat beberapa gua dihuni oleh spesies yang sama. Seperti Hipposideros ater dapat ditemukan di tiga lokasi (Gua Gale-gale, Gua Buwun dan Gua Raksasa) dari lima gua yang berada di wilayah selatan. Selain itu terdapat Phoniscus atrox dan Miniopterus pusillus ditemukan di Gua Buwun dan Gua Pantai Surga dan Miniopterus pusillus sendiri ditemukan di Gua Buwun, Gua Kenculit dan Gua Pantai Surga.

Hipposideros ater juga pernah ditemukan bertengger di beberapa gua di Indonesia diantaranya Gua Kars Gombong, Gua TNAP, Gua Lawa dan Gua Petruk (Wijayanti, 2010; Wijayanti, 2011; Riswandi, 2012 dan Nurfitrianto, 2013). Csorba,et al. (2008) menyebutkan bahwa Hipposideros atermerupakan spesies yang dapat beradaptasi dalam berbagai habitat. Berbeda halnya dengan spesies Phoniscus atrox dan Miniopterus pusillus, kedua spesies ini hanya ditemukan bertengger di dalam gua pada kondisi gua yang jauh dari gangguan dan kebisingan serta dekat dengan hutan primer dan daerah 
pertanian menyebabkan kedua spesies tersebur cenderung memilih gua yang memiliki kondisi alam yang hampir sama. Hutson, et al. (2008) dan Bumrungsri, et al. (2008) menyebutkan bahwa Phoniscus atrox pernah ditemukan di Thailand dengan status new record di dalam hutan cemara murni dekat daerah pertanian dan bertengger dibekas sarang burung dan gua berkapur. Sedangkan Miniopterus pusilluspernah ditemukan di gua yang berada di pegunungan Saung Desa Pengembur Kuta Lombok Tengah. Gua tersebut dikelilingi oleh daerah pertanian yang cukup subur. Dengan demikian, dapat disimpulkan bahwa gua-gua yang dihuni oleh spesies yang sama cenderung memiliki kondisi habitat yang sama yang disukai oleh spesies tersebut. Menurut Zahn \& Hager (2005) proses yang terlibat dalam memilih tempat bersarang cukup kompleks. Ketersediaan tempat bersarang yang cocok misalnya, akan mempengaruhi perilaku pencarian makan, tetapi perilaku bersarang sendiri juga dipengaruhi oleh kelimpahan dan penyebaran makanan.

Jumlah spesies kelelawar dalam satu gua yang ditemukan di gua-gua karst diIndonesia pada penelitianpenelitian sebelumnya terdiri dari satu sampai enam spesies kelelawar (Maryanto \& Maharadatunkamsi 1991; Saroni 2005; Pujirianti 2006; Apriandi 2006).Pada penelitian spesies kelelawar yang ditemukan di gua wilayah selatan Pulau Lombok terdiri atas 2 sampai lima spesies. Namun demikian pada penelitian yang dilakukan oleh Wijayanti (2011) di Gua Petruk kawasan Karst Gombong telah menemukan 9 spesies dalam gua tersebut.Pada penelitian spesies kelelawar di gua-gua yang terdapat di luar Indonesia menemukan satu sampai dengan tiga spesies dalam satu gua. Seperti penelitian Seckerdieck,et al. (2005) di GuaAlterberga Jerman hanya mendapatkan satu jenis kelelawar Rhinolophushipposideros Microchiroptera) bersarang dalam satu gua. Penelitian Dunn(1978) di Gua Anak Takun Malaysia; penelitian Duran \& Centano (2002) di GuaBonita India Barat; dan penelitian Zukal et al. (2005) di Gua KaterinskaChekoslovakia masing-masing menemukan dua jenis kelelawar yang bersarang dalamsatu gua. Penelitian Zahn dan Hager (2005) mendapatkan tiga jenis kelelawarbersarang dalam satu gua yang berlokasi di Bavaria Jerman. Dalam penelitian ini spesies kelelawar yang ditemukan menghuni satu gua terdiri dari dua sampai dengan 5 spesies.

Pada penelitian ini Gua Raksasa Tanjung Ringgit memiliki kekayaan spesies tertinggi dari gua lainnya yakni 5 spesies, selanjutnya diikuti oleh Gua Buwun Kuta sebanyak 4 spesies. Sedangkan Gua Gale-gale hanya dihuni oleh 3 spesies, Gua Pantai Surga 3 spesies, dan Gua Kenculit 2 spesies. Banyaknya spesies kelelawar yang menghuni Gua Raksasa dan Gua Buwun disebabkan oleh bervariasinya lingku-ngan gua yang terbentuk. Hal ini sesuai dengan pendapat Castillo,et al. (2009) yang menyatakan bahwa kondisi lingkungan di dalam satu gua dapat berbeda antara satu zona (mintakat) dengan zona lainnya, dan dapat menyebabkan pemisahan mikroklimat dalam ruang gua. Pemisahan mikroklimat tersebut dapat mengundang keanekara-gaman jenis makhluk hidup. Selain itu, banyaknya faktor ekologi yang berperan dan adanya berbagai model interaksi spesies yang terjadi dapat mengakibatkan terjadinya perubahan kekayaan spesies dan kemungkinan-kemungkinan ini sulit diprediksi (Hadiprayitno, 2012).

\section{KESIMPULAN}

Kekayaan spesies kelelawar gua wilayah selatan Pulau Lombok terdiri dari 6 famili dengan 12 spesies.Spesies tersebut diantaranya Macroglossus minimus, Eonycteris spelaea, Rousettus amplexicaudatus, Hipposederos bicolor, Hipposederos ater,Hipposederos diadema, Miniopterus pusillus, Phoniscus atrox,Murina cyclotis, Rhinolopus simplex, Taphozous melanopogon, dan Rhinopoma microphyllum.

\section{SARAN}

Spesies kelelawar Phoniscus atrox yang ditemukan dalam penelitian ini merupakan spesies terancam punah di Indonesia.Temuan ini menunjukkan bahwa wilayah selatan Pulau Lombok berperan penting dalam mendukung spesies kelela-war yang perlu mendapatkan perlindu-ngan. Karena itu, perlu dipikirkan untuk menjadikan beberapa gua yang ada di wilayah selatan Pulau Lombok direkomendasikan ntuk dijadikan sebagai kawasan konservasi.

\section{DAFTAR PUSTAKA}

Apriandi, J., Kartono, AP.,dan Maryanto. (2008). Keanekaragaman dan kekerabatan spesies kelelawar berdasarkan kondisi mikroklimat tempat bertenger pada beberapa goa di kawasan Gua Gudawang.J. Biol. Indo. 5(2): 121-134

Baudinette, R.V., Churchill, S.K., Christian,K.A., Nelson, J.E.,and Hudson, P.J. (2000). Energy, Water Balance And The Roost Microenvironment In Three Australian CaveDwelling Bats (Microchiroptera).J. Comp. Physiol. B, 170: 439-446

Corbet, GB.and JE Hill. (1992). The mammal of the Indomalayan region. Asystematic review. Natural history museum publications: Oxford University Press

Castillo,AE., Meneses, GC., Davilla-Montes, MJ., Anaya MM.,and Leon, PR. (2009). Seasonal distribution and circadian activity in the troglophile long-footed robber frog Eleutherodactylus longipes (Anura: Brachycephalidae) at LosRiscos Cave, Queretaro, Mexico: Field and laboratory studies. J. Cave andKarst Studies 71(1):121-128

Dunn, F.L. (1978). Gua Anak Takun Ecological Observation.The Malayan Nature J. 19(1): 75-87

Fajri, S. R.dan Hadiprayitno, G. (2013). Kelelawar Pulau Lombok. Proseding Seminar Nasional "Penelitian dan Pembelajaran Sains" Program Pascasarjana Universitas Mataram. 
Gunnell, A., Yani, M., Kitchener, D. (1996). Proceedings of the First International Conference on Eastern IndonesianAustralian Vertebrate Fauna. Perth, Australia: Western Australian Museum.

Hutson, A.M. and Kingston, T. (2008). Phoniscus atrox. In: IUCN 2014. IUCN Red List of Threatened Species. www.iucnredlist.org. 27/6/2014

Kitchener, D. J., Boeadi, Charlton, L.and Maharadatunkamsi. (2002). Mamalia Pulau Lombok. Bidang Zoologi Puslit Biologi-LIPI, The Gibbon Foundation Indonesia, PILINGO Movement. Bogor

Maryanto, I.and Maharadatunkamsi. (1991). Kecenderungan spesies spesies kelelawar dalam memilih tempat bertengger pada beberapa gua di Kabupaten Sumbawa.Media Konservasi. 3:29-34

Riswandi, Hafiz. (2012). Kelelawar Gua di TNAP.J. Biol. Indo. $5(2)$

Seckerdieck, A., Walther, B.,and Halle S. (2005). Alternative use of two different roosttypes by a maternity colony of the lesser horseshoe bat (Rhinolophushipposideros). Journal Mam. Biol. 8: 216-224

Suyanto, A. (2001). Kelelawar Indonesia. Puslitbang Biologi LIPI. Jakarta

Wijayanti. (2001). Komunitas Fauna Gua Petruk dan Gua Jatijajar Kabupaten kebumen Jawa Tengah.(Tesis tidak dipublikasikan: Progam Pasca Sarjana Universitas Indonesia Jakarta)

Wijayanti, F., Solihin, D., Ali Kodra, H.S dan Maryanto, I. (2010). Pengaruh fisik gua terhadap struktur komunitas kelelawar pada beberapa gua karst di gombong kabupaten kebumen jawa tengah.Jurnal Biologi Lingkungan Vol. 4(2)

Wijayanti, F. (2010). Kelimpahan, Sebaran, dan Keanekaragaman Spesies Kelelawar (Chiroptera) pada Beberapa gua dengan Pola Pengelolaan Berbeda di Kawasan Karst Gombong Kabupaten Kebumen Jawa Tengah. (Penelitian tidak dipublikasikan Dana RAB UIN Syarif Hidayatullah Jakarta)

Wijayanti, F. (2011). Biodiversitas dan Pola Pemilihan Sarang Kelelawar: Studi Kasus di Kawasan Karst Gombong Kabupaten Kebumen Jawa Tengah. Institut Pertanian Bogor.

Wijayanti, F. (2011). Ekologi, relung, pakan, dan strategi adaptasi kelelawar penghuni gua di karst gembong jawa tengah. (Disertasi tidak dipublikasikan Institut Pertanian Bogor)

Zahn, A.and Hager, I. (2005). A cave dwelling colony of Myotis daubentonii in Bavaria, Germani.Journal Mam. Biol. 70 : $242-165$ 